\title{
ASSESSMENT OF PHYSIOLOGICAL STRAIN IN MALE FOOD CROP CULTIVATORS ENGAGED IN MANUAL THRESHING TASK IN A SOUTHERN DISTRICT OF WEST BENGAL
}

\author{
Ayan Chatterjee ${ }^{* * *}$, Sandipan Chatterjee ${ }^{*}$, Neepa Banerjee ${ }^{*}$, Shankarashis Mukherjee ${ }^{* * * *}$ \\ * University of Calcutta, Human Performance Analytics and Facilitation Unit, Department of Physiology, \\ Kolkata, India \\ *** ICFAI University, Faculty of Allied Health Sciences, Kamalghat, Tripura, India \\ **** West Bengal State University, Public Health Analytics Unit, Department of Food and Nutrition, \\ Kolkata, India
}

corresponding author: Dr. Shankarashis Mukherjee, e-mail: phauhpafu@gmail.com

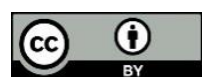

This work is licensed under a

Creative Commons Attribution 4.0

International License

Original scientific paper

Received: February $16^{\text {th }}$, 2020

Accepted: March 25 ${ }^{\text {th }}$, 2020

HAE-1938

https://doi.org/10.33765/thate.10.4.2

\begin{abstract}
The impact of rise in ambient temperature is not confined to output; it has an impact on the work performance of human beings associated with occupational activities in informal sector, especially those carried out in the open field under the sky. The agricultural workers are constrained to work manually all through the day irrespective of disparity in working situation existing in the working environment. Hence, there is an urgent need to study the cardiac performance status in terms of indicators of physiological strain of the human resources. In this backdrop, the present study has been undertaken to assess the degree of physiological strain in male food crop cultivators' (age range 24 - 36 years) engaged in manual threshing (separating the grains from the rice straw by manually - by hand i.e. beating method) during paddy cultivation time. Moreover the magnitude of physiological strain was significantly higher $(\mathrm{P}<0.5)$ during "Boro" type of paddy cultivating time. The result of the study indicated that human resources are indeed subjected to strains, albeit to different degree, as adjudged by the indicators of physiological strain.
\end{abstract}

Keywords: agriculture, wet bulb globe temperature (WBGT), heart rate, cardiovascular strain, workload

\section{INTRODUCTION}

The agriculture sector plays a pivotal role for sustainable growth and development of the Indian economy. Besides that, agriculture sector employs nearly half of the workforce of the country. Agriculture being an open air task, the agricultural workers has to perform different tasks throughout the year even in a single day, irrespective of variation in the thermal working environmental condition, including the disparity of thermal environmental status [1, 2]. Rice (Oryza sativa L.) is a plant belonging to the family of 
grasses, Gramineae. It is one of the major food crops of the world and forms the staple diet of about half of the world's population. The global production of rice has been estimated to be at the level of 650 million tonnes. Asia is the leader in rice production accounting for about $90 \%$ of the world's production. Among the Asian countries, India has a long history of rice cultivation [3 - 5]. Globally, it stands first in rice area and second in rice production. Paddy is grown all most all the states in India. Paddy cultivation involves ploughing, transplanting, reaping, threshing and parboiling. Most of the tasks in paddy cultivation is seasonal, and during summer harvest, workers often spend long hours under direct sun, in intense heat, performing arduous physical labour [4, 5]. And the earlier studies reported that physical work capacity and workperformance are getting affected due to unfavourable thermal conditions prevailing in the working environment in different occupations including agriculture [6]. The risks of excessive heat exposure are greater in tropical developing countries where large work forces perform manual and heavy tasks for long periods under very hot and humid conditions with minimal access to cooling intervention; India, being a tropical country is no exception to it. Additionally, it has also been reported that, physical work capacity and work-performance are getting affected due to adverse thermal conditions prevailing in the working environment in different occupations including agriculture. Hence, an increase in ambient temperature, a major determinant of thermal aspect of working environment, may have some impact on the occupational health profile on the individuals working in the open - air non-mechanized agricultural field daily for a considerable period of time. Therefore, different tasks performed by agricultural workers not only demand considerable time and energy but also sources of drudgery for the agricultural workers $[3,5,6]$. In this backdrop the present study has been undertaken to assess the cardiac response status in terms of indices of physiological strain in male food crop cultivators' while engaged in manual (beating the panicles on a hard or wooden surface) threshing task during "Aman" (the winter or monsoon paddy, known as "Aman", is grown from June to December) and "Boro" (the sowing time of summer paddy of "Boro" paddy is November to February and harvesting time is March to April) type of paddy cultivation time.

\section{EXPERIMENTAL}

Study area: Human resources engaged in paddy cultivating task in Arambagh subdivision in the district of Hooghly were approached for the present study, the protocol of which was approved by the Institutional human ethical committee.

Study population, inclusion and exclusion criteria: The study was carried out on consenting human resources with no known chronic disease history (self-reported) and having a minimum working experience of three years and regularly working for a period of six to six and half hours per day on an average in the agricultural field. The individuals who were carrying out manual threshing task during "Aman" (i.e. during October - middle of November) and "Boro" (i.e. during March - middle of April) type of paddy cultivation was considered for participation in the study. Data were obtained from 36 adult male paddy cultivators (age range of 24 - 36 years) while they were taking part in manual threshing task during "Aman" type of paddy cultivation; it constituted the threshing group A (TG-A). Data were again collected from 33 male individuals while they were taking part in manual threshing task during "Boro" type of paddy cultivation; it constituted the threshing group B (TG-B).

Recording of basic information: Information regarding their age (year), socio - economic status (SES) - assessed by using the Kuppuswamy's socioeconomic scale [7], and average working experience (year) were recorded in a pre-designed schedule.

Assessment of thermal environmental condition: Ambient temperature $\left(\mathrm{T}_{\mathrm{a}}\right)\left({ }^{\circ} \mathrm{C}\right)$, wet 
bulb temperature $\left(\mathrm{T}_{\mathrm{WB}}\right) \quad\left({ }^{\circ} \mathrm{C}\right), \quad$ globe temperature $\left(\mathrm{T}_{\mathrm{g}}\right)\left({ }^{\circ} \mathrm{C}\right)$ and natural wet bulb temperature $\left(\mathrm{T}_{\mathrm{nwb}}\right)\left({ }^{\circ} \mathrm{C}\right)$ were noted during the working hours in the agriculture field. The values of wet bulb globe temperature (WBGT) $\left({ }^{\circ} \mathrm{C}\right)$, corrected effective temperature (CET) $\left({ }^{\circ} \mathrm{C}\right)$, discomfort index (DI) $\left({ }^{\circ} \mathrm{C}\right)$ and predicted four hour sweat rate $\left(\mathrm{P}_{4} \mathrm{SR}\right)$ (lit) were determined.

Assessment of physical and physiological parameters: Anthropometric measurements stature $(\mathrm{cm})$ and body weight $(\mathrm{kg})$ were measured using anthropometric measurement set and a pre calibrated weighing scale respectively. Body mass index (BMI) was calculated. The heart rate pre- work $\left(\mathrm{HR}_{\text {Pre-work }}\right)$ $\left(\right.$ beats.min $\left.{ }^{-1}\right)$, pre - work systolic $\left(\mathrm{SBP}_{\text {Pre-work }}\right)$ and diastolic $\left(\mathrm{DBP}_{\text {Pre-work }}\right)$ blood pressure $(\mathrm{mm}$ $\mathrm{Hg}$ ) was recorded using automated blood pressure monitor and/or sphygmomanometer in the morning hours before the individuals started working.

Assessment of indicators of cardiac strain: Cardiac strain indicators in terms of peak heart rate $\left(\mathrm{HR}_{\text {peak }}\right)$ [8], net cardiac cost ( $\left.\mathrm{NCC}\right)$ (beats. $\mathrm{min}^{-1}$ ) [9], estimated energy expenditure (EEE) $\left(\mathrm{kcal}_{\mathrm{min}}{ }^{-1}\right)$ [10], and cardio vascular strain index (CSI) [11] were determined.

Assessment of heaviness of workload: The "heaviness" of work has also been adjudged in terms of $\mathrm{HR}_{\text {peak }}$ NCC, and EEE. The environmental and cardiac response data were collected at regular intervals during morning (6.15 - $9.00 \mathrm{am})$, around noon (10.00 am - 1 pm) and afternoon hours (3.00 - $5.00 \mathrm{pm})$ respectively referred to as first, second and third spell (S1, S2 and S3).

Data and statistical analysis: Data have been presented in $\mathrm{AM} \pm \mathrm{SD}$ form. Obtained data were analysed and presented graphically. Analysis of variance (ANOVA) was performed. As the thermal environmental conditions were assessed in terms of several indices, the correlations between them were found out. $\mathrm{P}$ value lower than $0.05(\mathrm{P}<0.05)$ was considered significant.

\section{RESULTS AND DISCUSSION}

General characteristics of both groups are presented in Table 1. There is no significant difference in respect of age (years), SES, and working experience (year).

Table 1. General characteristics of study participants

\begin{tabular}{|c|c|c|}
\hline Variables & TG-A & TG-B \\
\hline Age (years) & $26.8 \pm 2.12$ & $27.0 \pm 2.61$ \\
\hline SES $^{\wedge}$ & $\begin{array}{c}\text { Lower } \\
\text { Middle }\end{array}$ & $\begin{array}{c}\text { Lower } \\
\text { Middle }\end{array}$ \\
\hline $\begin{array}{c}\text { Working experience } \\
\text { (year) }\end{array}$ & $7.8 \pm 0.89$ & $7.7 \pm 0.68$ \\
\hline
\end{tabular}

$\mathrm{AM} \pm \mathrm{SD}, \wedge \mathrm{ns}$

The physical and physiological variables of the study participants are presented in Table 2 . TG-A and TG-B individuals do not differ significantly in terms of their stature $(\mathrm{cm})$, body weight $(\mathrm{BW})(\mathrm{kg})$, BMI $\left(\mathrm{kg} \cdot \mathrm{m}^{-2}\right), \mathrm{HR}_{\text {Pre- }}$ work $\left(\right.$ beats. $\left.\mathrm{min}^{-1}\right), \mathrm{SBP}_{\text {Pre-work }}(\mathrm{mm} \mathrm{Hg})$, and $\mathrm{DBP}_{\text {Pre-work }}(\mathrm{mm} \mathrm{Hg})$.

Table 2. Physical and physiological characteristics of the study participants

\begin{tabular}{|c|c|c|}
\hline Variables & TG-A & TG-B \\
\hline Stature $(\mathrm{cm})^{\wedge}$ & $163.0 \pm 4.11$ & $162.2 \pm 2.85$ \\
\hline $\mathrm{BW}(\mathrm{kg})^{\wedge}$ & $54.8 \pm 5.17$ & $55.2 \pm 5.05$ \\
\hline $\operatorname{BMI}\left(\mathrm{kg} \cdot \mathrm{m}^{-2}\right)^{\wedge}$ & $20.5 \pm 1.17$ & $21.0 \pm 4.02$ \\
\hline $\begin{array}{c}\mathrm{HR}_{\text {Pre-work }} \\
(\text { beats.min } \\
\text { be })^{-1}\end{array}$ & $69.0 \pm 5.19$ & $70.4 \pm 4.17$ \\
\hline $\begin{array}{l}\mathrm{SBP}_{\text {Pre-work }} \\
(\mathrm{mm} \mathrm{Hg})^{\wedge}\end{array}$ & $118.0 \pm 5.19$ & $117.4 \pm 5.11$ \\
\hline $\begin{array}{l}\mathrm{DBP}_{\text {Pre-work }} \\
(\mathrm{mm} \mathrm{Hg})^{\wedge}\end{array}$ & $72.0 \pm 7.01$ & $71.7 \pm 6.11$ \\
\hline
\end{tabular}

$\mathrm{AM} \pm \mathrm{SD}, \wedge \mathrm{ns}$

The mean values of BMI of TG-A and TG-B individuals are $20.5 \mathrm{~kg} . \mathrm{m}^{-2}$ and $21.0 \mathrm{~kg} \cdot \mathrm{m}^{-2}$; which indicated that, the participants were in "normal weight" category as per the classification given by World Health Organization (WHO) [12]. This finding is not surprising as the human resources participating in the present study were carrying out manual threshing tasks during paddy cultivation time, as earlier studies observed that, individuals taking part regularly even in different form of 
recreational physical activity in a planned and systematic way have beneficial role in achieving favourable body composition, enhancing fitness and hence facilitate maintaining a normal BMI [13 - 16]. Higher values of BMI have also been found to be associated with more chance of work related musculoskeletal disorder among sedentary workers $[17,18]$.

The environmental condition in terms of three indicators of thermal environmental status WBGT, CET, DI and $\mathrm{P}_{4} \mathrm{SR}$ are presented in Figure 1.

In case of TG-A individuals, the average values of WBGT index, during "Aman" type of paddy cultivating time in $\mathrm{S} 1, \mathrm{~S} 2$ and $\mathrm{S} 3$ working spells were $19.0^{\circ} \mathrm{C}, 22.2^{\circ} \mathrm{C}$, and 20.0 ${ }^{\circ} \mathrm{C}$ respectively. There was no restriction recommended against carrying out the task. In case of TG-B individuals i.e. during "Boro" paddy cultivating time the average WBGT values in S1, S2 and S3 working spells were $27.1{ }^{\circ} \mathrm{C}, 35.6{ }^{\circ} \mathrm{C}$, and $34.4{ }^{\circ} \mathrm{C}$ respectively; ideally, no work would be allowed under conditions recorded during S2 and S3 as per American Conference of Governmental Industrial Hygienists (ACGIH) guideline [19]. Whereas in the S1 working spell for "light" type of work, there is no restriction in terms of allocation of work in work-rest cycle; for "moderate" type of work, up to $75 \%$ time each hour, work can be allocated in work rest cycle and for "heavy" type of work, up to 50 $\%$ time each hour, work could be allocated in work rest cycle [20]. The average values, during "Aman" paddy cultivating time, of corrected effective temperature (CET), along the spells were $17.3{ }^{\circ} \mathrm{C}, 20.4{ }^{\circ} \mathrm{C}$, and $19.3{ }^{\circ} \mathrm{C}$. There is no restriction for carrying out the task along the working spells i.e. in S1, S2, and S3 working spells. During "Boro" type of paddy cultivating time, average values of CET in S1, $\mathrm{S} 2$, and S3 working spells were $28.2^{\circ} \mathrm{C}, 32.1$ ${ }^{\circ} \mathrm{C}$, and $31.1{ }^{\circ} \mathrm{C}$ respectively, out of which in the S2 (with average CET value $32.1^{\circ} \mathrm{C}$ ) no work would ideally be allowed. In S3 (with average CET value $31.1{ }^{\circ} \mathrm{C}$ ), up to "light" category of work could be allowable [21, 22]. During the "Aman" type of paddy cultivating time with an average DI values in $\mathrm{S} 1, \mathrm{~S} 2$, and S3 working spells were $19.5^{\circ} \mathrm{C}, 23.7^{\circ} \mathrm{C}$, and $21.0^{\circ} \mathrm{C}$.

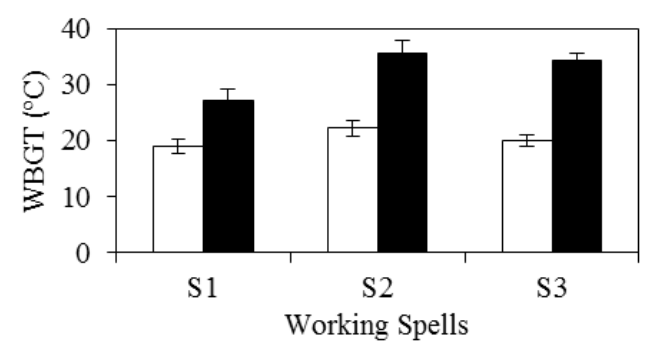

a)

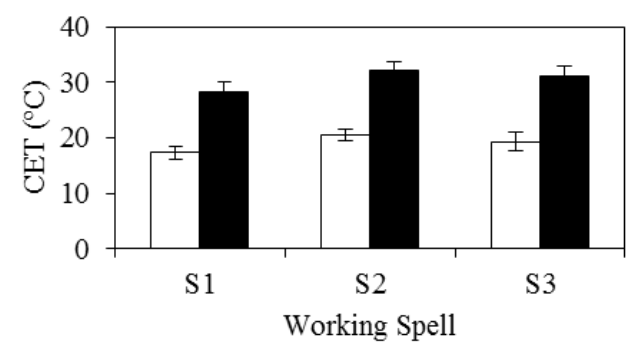

b)

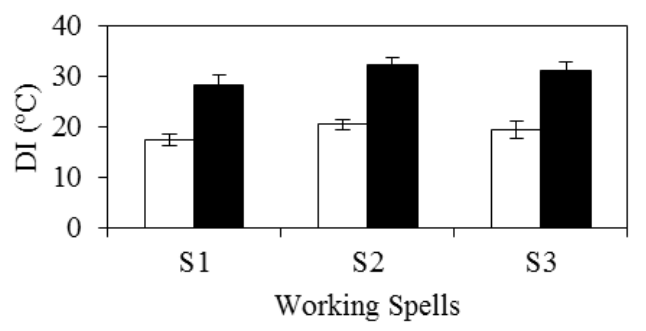

c)

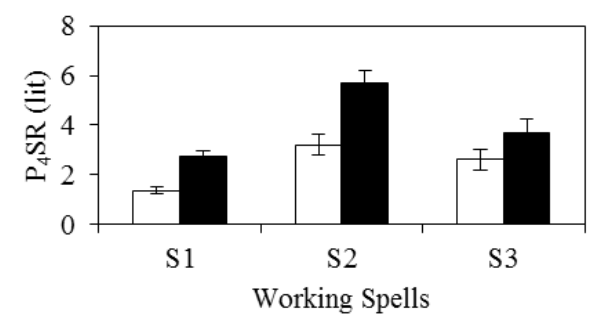

d)

Figure 1. Thermal environmental status along the working spells: a) WBGT, b) CET, c) DI, d) $\mathrm{P}_{4} \mathrm{SR}(\square$ TG-A, $\square$ TG-B)

There was also no restriction of carrying out the task throughout the working spell. During "Boro" type of paddy cultivating time the average DI values in S1, S2 and S3 were 26.0 ${ }^{\circ} \mathrm{C}, 31.5{ }^{\circ} \mathrm{C}$ and $30.5^{\circ} \mathrm{C}$. During S2 and S3, heat load is considered "severe", and human resources engaged in physical work are at 
increased risk for heat illness. In S1 working spell with average DI values of $26.0{ }^{\circ} \mathrm{C}$, the heat load is considered "moderate" and individuals can perform the physical work some difficulties $[23,24]$. During the "Boro" paddy cultivating time the limit in the $\mathrm{S} 2$ and S3 working spell in terms of $\mathrm{P}_{4} \mathrm{SR}$ for acclimatized human resources is clearly exceeded [25]. The environmental condition of the present study has been adjudged by four well known indicators of thermal environmental condition - WBGT, CET, DI and $\mathrm{P}_{4} \mathrm{SR}$; however the values of these four indices are indicating similar environmental status. This is further affirmed by significant positive correlation among these indices (WBGT and CET $(\mathrm{P}<0.05)$, WBGT and DI ( $\mathrm{P}<0.05)$, WBGT and $\mathrm{P}_{4}$ SR $(\mathrm{P}<0.05)$, CET and $\mathrm{P}_{4} \mathrm{SR}(\mathrm{P}<0.05)$, CET and DI $\left.(\mathrm{P}<0.01)\right)$. From the result of the present study it has been clearly observed that the individuals working in the agricultural field would feel very hot and uncomfortable most of the day time, especially at around noon, i.e. during the second spell. Moreover, the global climate change is increasing and average temperatures are becoming more extreme. This is of great significance in various locations of India which already remain hot in most months of the year; this also directly affects the occupational health status and the work output of the human resources engaged in different type of outdoor occupational task. With continuation of work for long time in such adverse environmental condition, especially during the "Aman" and "Boro" type of paddy cultivation, and particularly during the second and third spell of the working hours, there is a risk of different degrees of physiological strain among the study participants.

Cardiac response profile of the study participants adjudged by using strain indicators, i.e. by using $\mathrm{HR}_{\text {Peak }}$ (beats. $\min ^{-1}$ ), NCC, EEE and CSI. The results of the physiological strain in terms of $\mathrm{HR}_{\text {peak }}$ NCC, EEE and CSI for the TG-A and TG-B individuals have been presented in Figure 2.

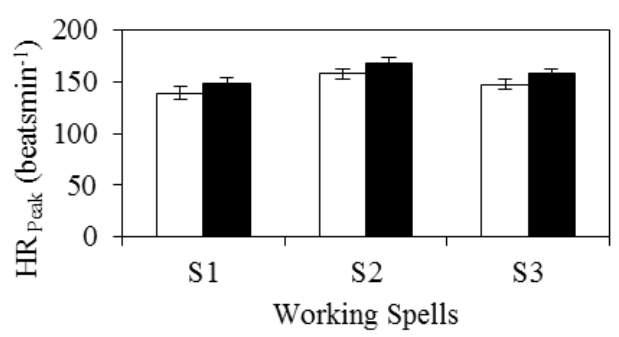

a)

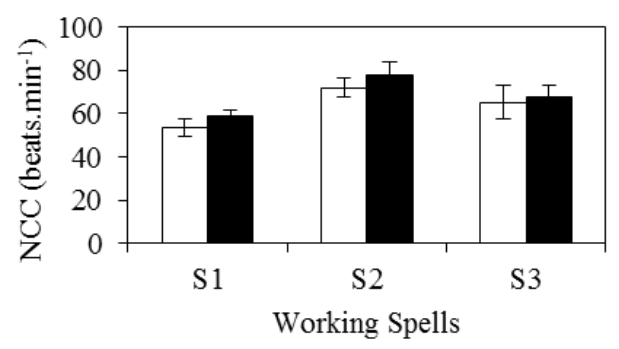

b)

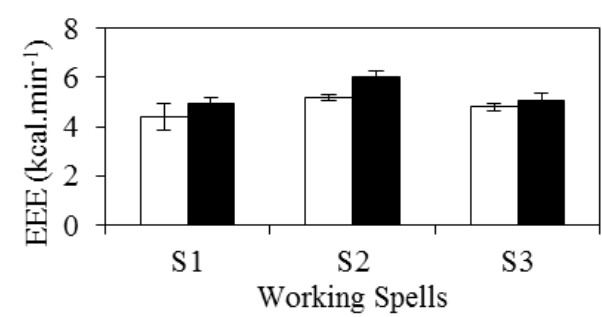

c)

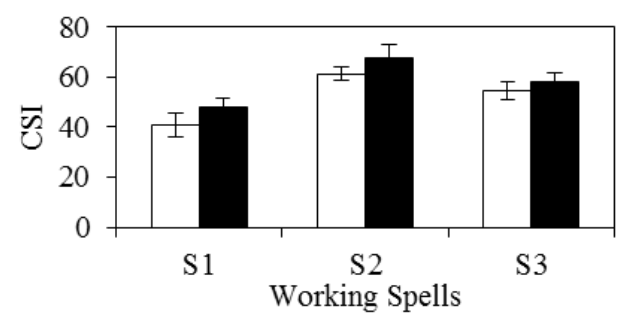

d)

Figure 2. Comparison of cardiac response status in terms of different indicators of physiological strain along working spells:
a) $\mathrm{HR}_{\text {Peak }}$, b) NCC, c) EEE, d) CSI ( $\square$ TG-A, $\square$ TG-B)

In case TG-A individuals, in terms of $\mathrm{HR}_{\text {Peak }}$ (beats. $\min ^{-1}$ ), it is found that in the paddy cultivators during the "Aman" type of paddy cultivating time, the values varied from 135 144 beats. $\mathrm{min}^{-1}$ in the first working spell, i.e. in S1 working spell, whereas during the S2 and S3 it varied from 153 - 162 beats. $\mathrm{min}^{-1}$, 143 - 152 beats. $\mathrm{min}^{-1}$ respectively. In terms of NCC, expressed in beats.min ${ }^{-1}$, it is found that during the "Aman" type of paddy cultivation, the values varied from 49 to 58 beats. $\mathrm{min}^{-1}$ in 
the first working spell, i.e. in S1 working spell whereas during the S2 and S3 it varied from 65 to 78 beats. $\min ^{-1}$ and $61-69$ beats. $\min ^{-1}$ respectively. In terms of EEE, expressed in kcal.min ${ }^{-1}$, it is found that the values of EEE varied from 4.35 to $4.43 \mathrm{kcal} . \mathrm{min}^{-1}$ in the first working spell, i.e. in S1 working spell, whereas during the $\mathrm{S} 2$ and $\mathrm{S} 3$ it varied from 5.15 to $5.25 \mathrm{kcal}_{\mathrm{min}}{ }^{-1}$ and 4.78 to 4.86 kcal. $\mathrm{min}^{-1}$ respectively. CSI value varied from $38-47,57-66$ and $50-59$ in the S1, S2 and $\mathrm{S} 3$ respectively.

In case of TG-B individuals, in terms of $\mathrm{HR}_{\text {Peak }}$ (beats. $\min ^{-1}$ ), it is found that in the paddy cultivators during the "Boro" type of paddy cultivating time, the values varied from 144 to 153 beats. $\mathrm{min}^{-1}$ in the first working spell, i.e. in S1 working spell, whereas during the S2 and S3 it varied from $163-172$ beats.min ${ }^{-1}$ and $152-161$ beats. min $^{-1}$ respectively. In terms of NCC, expressed in beats. $\min ^{-1}$, it is found that, during the "Boro" type of paddy cultivation, the values varied from 54 to 63 beats. $\mathrm{min}^{-1}$ in the first working spell, i.e. in S1 working spell whereas during the $\mathrm{S} 2$ and $\mathrm{S} 3$ it varied from $74-81$ beats.min ${ }^{1}, 63-71$ beats. $\mathrm{min}^{-1}$ respectively. In terms of EEE, expressed in kcal.min ${ }^{-1}$, it is found that the values of EEE varied from 4.90 to 5.02 kcal.min ${ }^{-1}$ in the first working spell, i.e. in S1 spell, whereas during the S2 and S3 it varied from 5.97 to $6.06 \mathrm{kcal} . \mathrm{min}^{-1}$ and $4.91-5.02$ kcal. $\mathrm{min}^{-1}$ respectively. The CSI value varied from 37 to 47, 57 - 66, and 50 - 60 in the S1, S2 and S3 spell respectively.

In terms of workload for TG-A individuals, i.e. during the "Aman" type of paddy cultivating time, the heaviness of workload in the S1 working spell has been adjudged as "very heavy", "heavy" and "heavy" respectively in terms of three indicators $\mathrm{HR}_{\text {peak }}, \mathrm{NCC}$, and EEE. In the S2 working spell, the workload has been adjudged as "extremely heavy", "heavy" and "heavy" in terms of $\mathrm{HR}_{\text {peak }}, \mathrm{NCC}$, and EEE. In S3 working spell the workload has been adjudged as "very heavy", "heavy" and "heavy" respectively in terms of three indicators $\mathrm{HR}_{\text {peak }}$, NCC, and EEE.
In case of TG-B individuals i.e. during "Boro" type of paddy cultivating time, the heaviness of workload has been adjudged as "very heavy", "heavy", and "heavy" respectively in terms of three indicators $\mathrm{HR}_{\text {peak }}, \mathrm{NCC}$, and EEE. In the S2 working spell the workload has been adjudged as "extremely heavy", "heavy" and "very heavy" in terms of three indices of physiological strain - $\mathrm{HR}_{\text {peak }}, \mathrm{NCC}$, and EEE. In the S3 working spell the workload has been adjudged as "extremely heavy", "heavy" and "heavy" respectively in terms of $\mathrm{HR}_{\text {peak }}, \mathrm{NCC}$, and EEE. The finding of the present study was in consonance with the finding of an earlier study carried out among male paddy cultivators in Maharashtra [26]. It was observed that the human resources experienced highest degree i.e. "extremely heavy" degree of physiological strain while engaged in manual paddy threshing task compared with the other task during paddy cultivation period - ploughing (dry and wet ploughing) [1, 2, 27 - 30], transplanting (manual) [2, 3, 31, 32], threshing (by mechanized thresher and electrically driven paddy thresher) $[4,6,33,34]$ and reaping (manual) [35 - 37] parboiling [5]. Moreover, manual threshing during "Boro" type of paddy cultivation is more strenuous task compared to the others tasks during the paddy cultivating time in terms of the physiological strain. In the light of the observations presented, it may be mentioned that agriculture particularly being an open air work is strenuous, as adjudged in terms of so many indicators of physiological strain like HR Peak (beats.min ${ }^{-1}$ ), NCC (beats.min ${ }^{-1}$ ), EEE (kcal.min ${ }^{-1}$ ), and CSI, the degree of difficulty is rising with adverse impacts due climate change caused among other by global warming being on the rise. The strain has been found to be more in TG-A individuals, compared to the TG-B counterparts. Moreover, the workers were ignorant about the balance between work ability and job demand which could be attributed to the lack of awareness on health and safety issues. Moreover, the socioeconomic status compelled the workers to be least concerned for their health and working situation. 


\section{CONCLUSION}

From the present study it may be concluded that the agricultural work - paddy cultivation is a strenuous task. Moreover, the thermal environmental conditions adjudged by the heat indices are not favourable, i.e. they are above the recommended threshold values, making the task laborious for the human resources. It may be also mentioned that physiological strain was significantly higher in threshing - B (TGB) individuals, i.e. during "Boro" type of paddy cultivating time compared to their age matched threshing - A (TG-A) counterpart. Since agriculture is an open sky occupation and manual threshing is one of the strenuous tasks in paddy cultivation, there is a need for simultaneous attempt to use more human factor designed devices than absolutely being dependent on manual effort.

\section{REFERENCES}

[1] A. Chatterjee, S. Chatterjee, N. Banerjee, S. Chatterjee, S. Mukherjee, Climate Change and Human Performance: A Study in Bengalee Male Agricultural Workers, International Journal of Innovative Knowledge Concepts 7(2019) 1, 72-80.

[2] A. Chatterjee, N. Banerjee, S. Chatterjee, S. Chatterjee, S. Mukherjee, A Study to Assess Cardiac Response Indices in Food Crop Cultivation Task in West Bengal: Possible Implications of Climate Change, International Journal of Innovative Knowledge Concepts 7(2019) 5, 238-243.

[3] A. Chatterjee, N. Banerjee, S. Chatterjee, S. Chatterjee, S. Mukherjee, Impact of Variation in Working Environmental Condition on Cardiac Response Profile in Bengalee Male Crop Cultivators of a Southern District of West Bengal, Journal of Emerging Technologies and Innovative Research 6(2019) 6, 438-443. http://doi.one/10.1729/Journal.21469.

[4] A. Chatterjee, S. Chatterjee, N. Banerjee, S. Chatterjee, S. Mukherjee, Assessment of Cardiac Strain in Male Paddy
Cultivators Using two Different Type of Paddy Thresher: A Comparison, Indian Agriculturist 63(2019), 49-55.

[5] A. Chatterjee, S. Chatterjee, S. Chatterjee, N. Banerjee, S. Mukherjee, Diurnal Variation in Thermal Working Environment, Workload and Physiological Strain in Women Workforces Engaged in Manual Parboiling Task, in: Advance Technologies in Agriculture for Doubling Farmers' Income, ed. K. Swain, New Delhi Publisher, 2018, 199210.

[6] A. Chatterjee, S. Chatterjee, S. Chatterjee, S. Bhattacharjee, T. Santra, N. Banerjee, K. Ghosh, S. Mukherjee, Assessment of Physiological Strain in Male Cultivators Engaged in Mechanized Threshing Task Using Two Different Types of Threshers, Science and Culture 84(2018) 5-6, 199-205.

[7] B.P. Ravikumar, S.R. Dudala, A.R. Rao, Kuppuswamy's Socio-Economic Status Scale - A Revision of Economic Parameter for 2012, International Journal of Research and Development of Health 1(2013) 1, 2-4.

[8] P.O. Astrand, K. Rodhal, Threshold Limit Values and Biological Exposure Indices, Text Book of Work Physiology, McGraw Hill, New York, 1986.

[9] A. Chamoux, A.M. Borel, P. Catilina, Pour la standardisation d'une fréquence cardiaque de repos: la fréquence cardiaque de repos nocturne. Implications dans l'évaluation de la charge de travail, Archives des maladies professionnelles de médecine du travail et de sécurité sociale 46(1985) 4, 241250.

[10] N.L. Ramanathan, S.R. Dutta, B.N. Roy, A. Chatterjee, L.N. Mullick, Energy Cost of Different Muscular Tests Performed by Indian Subject, Indian Journal of Occupational Health 10(1967), 253-261.

[11] D.G. Trites, D.G. Robinson, E.W. Banister, Cardiovascular and Muscular Strain during a Tree Planting Season among British - Columbia Silviculture 
Workers, Ergonomics 36(1993) 8, 935949.

[12] WHO, Obesity: Preventing and Managing the Global Epidemic, Report of a WHO Consultation on Obesity, Technical Report Series, No. 894, World Health Organization, Geneva, Switzerland, 256, 2000.

[13] S. Mukherjee, N. Banerjee, S. Chatterjee, S. Chatterjee, Effect of Practicing Select Indian Classical Dance Forms on Body Composition Status of Bengalee Females: an Anthropometric Study, Indian Journal of Biological Sciences 20(2014), 40-48.

[14] S. Mukherjee, N. Banerjee, S. Chatterjee, S. Chatterjee, Effect of Kathak Dancing on Obesity Indices in Women of Sedentary Avocations, Science and Culture 80(2014) 9-10, 279282.

[15] S. Mukherjee, N. Banerjee, S, Chatterjee, B. Chakraborti, Impact of Bharatnattyam Dancing Exercise on Reducing Central Obesity in Adult Bengalee Females, Science and Culture 79(2013) 11-12, 503-506.

[16] A. Chatterjee, S. Chatterjee, N. Banerjee, T. Santra, P. Mondal, S. Mukherjee, Evaluation of Body Composition and Somatic Profile in Male Individuals: A Comparison between Tribal and Non Tribal Agricultural Human Resources, Proceedings of the National Conference on Agriculture and Rural Development Issues in Eastern India, ISI Giridih, 2015, 25-26.

[17] A. Chatterjee, S. Chatterjee, S. Chatterjee, T. Santra, N. Banerjee, S. Mukherjee, Musculoskeletal Discomfort in Computer Operators of Organized Sector: Tracing the Link with Obesity Status, International Physiology 3(2015) 1, 23-28.

https://dx.doi.org/10.21088/ip.2347.1506 .3115.3.

[18] A. Chatterjee, S. Chatterjee, T. Santra, S. Mukherjee, The Influence of Anthropometric Variables for Development of Musculoskeletal Discomfort among Computer Operators in Organized Sectors, in: User Centered Design and Occupational Wellbeing, ed. D. Chakrabarti, S. Karmakar, McGraw Hill Education, New Delhi, 2014, 499503.

[19] ACGIH, Threshold Limit Values and Biological Exposure Indices, Cincinnati, Ohio, 2008.

[20] V.S. Miller, G.P. Bates, The Thermal Work Limit is a Simple Reliable Heat Index for the Protection of Workers in Thermally Stressful Environments, The Annals of Occupational Hygiene 51(2007) 6, 553-561.

[21] R. Brake, G.A. Bates, A Valid Method for Comparing Rational and Empirical Heat Stress Indices, The Annals of Occupational Hygiene 46(2002) 2, 165 174.

[22] World Health Organization, Health Factors Involved in Working under Conditions of Heat Stress: Report of a WHO scientific group, WHO technical report series, 412, 1969.

[23] Y. Epstein, D. Moran, Thermal Comfort and the Heat Stress Indices, Industrial Health 44(2006) 3, 388-398.

[24] E. Sohar, D.J. Tennenbaum, N. Robinson, A comparison of the cumulative discomfort index (Cum DI) and cumulative effective temperature (Cum ET), as obtained by meteorological data, in: Biometeorology, ed. S.W. Tromp, Pergamon Press, Oxford, 1962, 395-400.

[25] B. McArdle, W. Dunham, H.E. Holling, W.S.S. Ladell, J.W. Scott, M.L. Thomson, J.S. Weiner, The Prediction of Effects of Warm and Hot Environments: The $\mathrm{P}_{4} \mathrm{SR}$ Index, Medical Research Council, RNP Report 47/391, London, England, 1947.

[26] P.K. Nag, P. Dutta, A. Nag, T. Kjellstrom, Extreme Heat Events: Perceived Thermal Response of Indoor and Outdoor Workers, International Journal of Current Research and Review 5(2013) 17, 65-78.

[27] A. Chatterjee, S. Chatterjee, S. Chatterjee, N. Banerjee, T. Santra, S. Mukherjee, Thermal Comfort and HSI: 
A Study in Bengalee Male Paddy Cultivators, Quad Scientific Reporter (2015), 148-155.

[28] A. Chatterjee, S. Chatterjee, S. Chatterjee, T. Santra, S. Bhattacharjee, S. Mukherjee, Exposure to Heat from Natural Working Environment and Cardiovascular Strain: A Study in Male Agricultural Workers in southern Bengal, Proceeding of $13^{\text {th }}$ International Conference on Humanizing Work and Working Environment 2015, Ergonomics in Caring for People, ed. G.G. Ray, R. Iqbal, A.K. Ganguli, V. Khanzode, December 7-9, 2015, Mumbai, India, 166-171.

[29] A. Chatterjee, N. Banerjee, S. Chatterjee, T. Santra, K.M. Agrawal, S. Mukherjee, Assessment of Physiological Strain in Male Paddy Cultivators due to Work and Exposure to Fluctuation in Thermal Conditions in Working Environments, Survey 55(2015) 3-4, 91-98.

[30] A. Chatterjee, S. Chatterjee, S. Chatterjee, S. Bhattacharjee, N. Banerjee, S. Mukherjee, Work Place Heat Exposure and Cardiovascular Status: A Study in Male Paddy Cultivators, in: Molecular Physiological and Nutritional Responses during Pathological Alteration of Cell Function, ed. P. Ghosh, B. Giri, Aaheli Publisher, Kolkata, 2017, 110-112.

[31] A. Chatterjee, S. Chatterjee, N. Banerjee, S. Chatterjee, T. Santra, S. Mukherjee, Assessment of Physiological Strain due to Work and Exposure to Heat of Working Environments in Male Paddy Cultivators, Advances in Applied Physiology 1(2016) 1, 8-11. http://doi:10.11648/j.aap.20160101.12.

[32] A. Chatterjee, S. Chatterjee, S. Bhattacharjee, T. Santra, N. Banerjee, S. Mukherjee, Assessment of Postural Discomfort in Male Paddy Cultivators in Southern Bengal, in: Technology Enabled Workplace Design, Excel India: 7, 2018.

[33] A. Chatterjee, S. Chatterjee, N. Banerjee, T. Santra, S. Chatterjee, S. Mukherjee, Assessment of Thermal Working
Environmental Condition and Cardiac Response Indicators in Male Agricultural Workers Engaged in Traditional Manual Paddy Threshing Task, in: Technology Enabled Workplace Design, Excel India: 6, 2018.

[34] A. Chatterjee, S. Chatterjee, S. Chatterjee, N. Banerjee, S. Mukherjee, A Comparative Study on the Impact of Thermal Working Environmental Factors and Workload on Cardiac Response Indicators in Male Food Crop Cultivators of Two Ethnic Groups, Indian Journal of Biological Sciences 24(2018), 31-44.

[35] A. Chatterjee, S. Chatterjee, S. Chatterjee, T. Santra, N. Banerjee, S. Mukherjee, Assessment of Physiological Strain Due to Work and Exposure to Different Thermal Working Environmental Condition in Male Paddy Cultivators of a Southern District of West Bengal, in: Ergonomics for Improved Productivity, Excel India: 195, 2017.

[36] A. Chatterjee, S. Chatterjee, N. Banerjee, S. Chatterjee, T. Santra, S. Mukherjee, Seasonal Distribution of Thermal Comfort: A Study to Assess Physiological Strain in Male Paddy Cultivators in Southern Bengal, Proceedings of the $14^{\text {th }}$ International Conference on Humanizing Work and Work Environment 2016, ed. L. Pal Singh, S. Singh, A. Bhardwaj, National Institute of Technology Jalandhar, December 8 - 11, 2016, Jalandhar, Punjab, India, 157-162.

[37] A. Chatterjee, S. Chatterjee, N. Banerjee, S. Mukherjee, Impact of Variation in Thermal Working Environmental Condition on Cardiac Response Indices in Male Human Resources Engaged in Food Crop Cultivation Task, Journal of Climate Change 6(2020) 1, 59-66. http://doi:10.3233/JCC200007.

\section{Acknowledgements}

We are thankful to all volunteers for their participation. 